\title{
SUPPRESSIVE AS COMPARED WITH ANALGESIC HORMONAL THERAPY IN PATIENTS WITH RHEUMATOID ARTHRITIS*
}

\author{
BY \\ LAURANCE W. KINSELL \\ Institute for Metabolic Research, Highland Alameda County Hospital, Oakland, California
}

(RECEIVED FOR PUBLICATION AUGUST 3, 1954)

About 25 years ago, I first became vaguely aware of the existence of the adrenal cortex. During the intervening quarter century, if any one fact concerning this organ has impressed itself upon me, it is the ubiquitous nature of the participation of its secretions in cellular and extracellular metabolism. The adrenal hormones are concerned in carbohydrate, protein, fat, fluid, and electrolyte metabolism; in immunological processes, with particular reference to the inflammatory reaction; and in the functional activity of every system in the body, including the central nervous system.

Following the stimulating observations of Hench, Kendall, Slocumb, and Polley (1949), many of us who had had small amounts of corticotropin sitting on our laboratory shelves for months, without any brilliant ideas as to how to use it in human subjects, found ourselves besieged with appeals to administer this material to arthritics. As a result, for a certain time patients with sore joints tended to displace dwarfs and giants in the beds of many metabolic wards.

It is the working philosophy in our Institute to select for admission to our precious metabolic beds patients whom we can help and from whom we can learn. Accordingly, we admitted patients with severe but potentially reversible joint damage, who, in return for such help as we might be able to give them, were willing to put up with the inconveniences of tube feeding and frequent blood-lettings, as part of long-term studies designed to evaluate the effect of $\mathrm{ACTH}$, cortisone, and later hydrocortisone, upon

- Presented by invitation at the annual meeting of the American Rheumatism Association, San Francisco, June 18, 1954. See p. 354. This work has been supported in part by grants from the Armour Laboratories and Merck and Company. It was carried out in association with members of the Institute for Metabolic Research including Harry E. Balch, Nadine Foreman, Marjorie Coelho, and Florence Olson.

Grateful acknowledgement is made to the Armour Laboratories for supplies of ACTH; to Merck and Company for supplies of cortisone and hydrocortisone; and to the Schering Corporation for supplies of oestrogen and testosterone. certain aspects of fat metabolism. In order to avoid changes of questionable magnitude in the chemical entities under study, quite intensive hormonal dosage was employed during these studies. With such dosage, in a clinical sense, two things became apparent:

(1) All evidence of activity of the arthritic process disappeared in a matter of days (and reappeared rapidly if the dosage was decreased too rapidly or discontinued).

(2) Specific dietary factors played a major role in determining whether the untoward effects of intensive dosage of the hormones would be present in minimal or maximal degree. Specifically, it became increasingly clear that if large amounts of the hormones were to be administered, diets high in protein, high in potassium, adequate in calories, and low in sodium and carbohydrate, were mandatory. The reasons for administering protein and potassium and withholding sodium are readily explained. The basis for the increased incidence of Cushingoid manifestations with increase of dietary carbohydrate is still by no means clear. On the basis of clinical observation, however, a cause-and-effect relationship appears to exist.

Having instituted hormonal therapy in a group of arthritic patients, we were committed, insofar as we were able, to maintain them on a therapeutic programme compatible with maximal usefulness to themselves and to the community. Also, with the progress of months, we were faced with a significant number of patients with severe, but potentially reversible, joint damage, who could not be admitted to the metabolic ward. Having started with intensive or, if you will, completely suppressive therapy for the reasons noted above, we decided to continue it with these patients whom we accepted primarily for treatment, rather than for controlled metabolic studies.

\section{Material}

The observations which follow are derived from a total of 54 patients, all with severe rheumatoid arthritis (except as noted below), and potentially "salvageable". 
The Table summarizes the treatment given and complications encountered. As indicated, some have been under continuous treatment since 1950 . One fact stands out most prominently: in not one patient have we been able to discontinue hormonal therapy completely.

\section{TABLE}

SUMMARY OF OBSERVATIONS IN PATIENTS WITH RHEUMATOID ARTHRITIS TREATED SINCE 1950

(Mean duration of therapy 16 months)

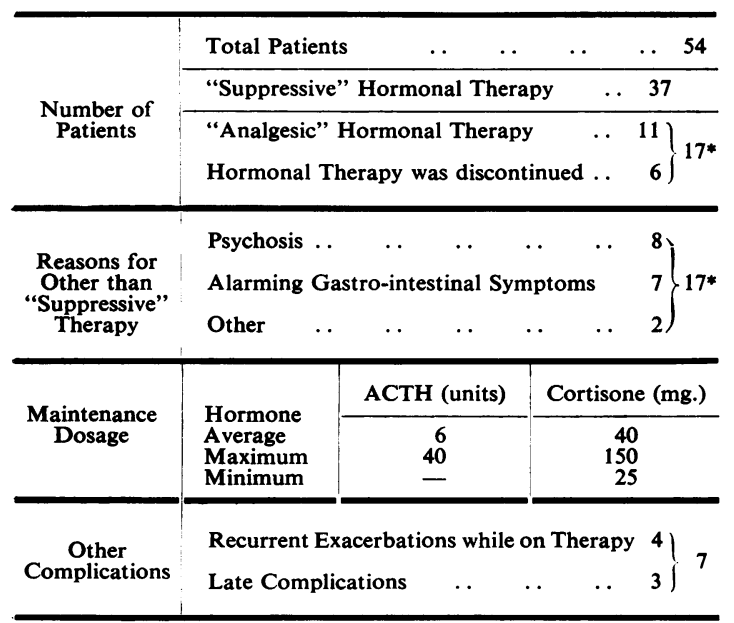

* In these seventeen patients (of the original 54), it became apparent during the first few days or weeks of treatment that large dosage hormonal therapy would not be tolerated. Accordingly, they were placed on "analgesic" or no hormonal therapy as indicated in each individual case.

\section{Results}

Before going into specific problems encountered in a few selected patients, I should like to consider with you some general observations:

(1) In approximately three of every ten patients, intensive hormonal therapy proved to be impossible, for one or both of two reasons:

(a) Mental aberration.

(b) Abdominal discomfort of more than minimal degree.

Of the total number of arthritics whom we have seen the pattern of therapy has been changed from a suppressive to an analgesic variety in eleven, and hormonal therapy has been stopped in six.

(2) In a small group of patients Cushingoid manifestations appeared despite excellent adherence to diet. In some of them, the difference between 500 and $200 \mathrm{mg}$. sodium per day is critical. A constant diet containing less than $200 \mathrm{mg}$. sodium is unattrac- tive to say the least. The administration of very large amounts of potassium (20 to $40 \mathrm{~g}$. potassium chloride daily) may permit of a larger sodium intaken. in some; in others mercurial diuretics, in conjunction: with high potassium intake, may be necessary.

(3) One may set up a reasonably sound "standard' programme for initial therapy of these patients as follows:

(a) Hospitalization for a period of 10 days tôn 2 weeks.

(b) Hormonal therapy of sufficient intensity during the first week to bring the sedimentation rate taw normal and to cause a disappearance of all pain and swelling in the involved joints.

(c) Progressive decrease in dosage during the remaining period of hospitalization to an amount $\triangleright$ compatible with the maintenance of a completei clinical remission.

(d) During hospitalization, the patient receives fulf instruction in the principles and practice of dietand medication.

(4) The establishment of a standard pattern of dosage for long-term maintenance is by no mean absolute. Two individuals, each having arthritis of apparently equal severity, may have dosage requge ments which vary by as much as 300 to 400 per cent: ${ }^{+}$ by the end of the second month of treatment. GुrD average programme is shown in the Figure (opposite)

(5) The majority of patients who are likely t\& develop mental or gastro-intestinal difficulties will do so during the period of initial intensive hormonat therapy. Hence, during their period of hospitaliza 3 tion, it may be decided whether minimal analgesie therapy or no hormonal therapy is to be used. A occasional patient will do well during the hospitas period, and then run into serious difficulty a fews weeks or even a few months later. It is our imprese sion that in at least some of these individuals, the appearance of mental, gastro-intestinal, or severe Cushingoid manifestations is referable to a break in the programme of adherence to diet.

(6) Oestrogen and/or testosterone may be of reap value in the total programme. This applies par ticularly to menopausal women and elderly menor Inhibition of ovulation with oestrogen may preven 0 extreme accentuation of salt and water retention in w the late progestational phase of the menstrual cycle

\section{Specific Cases}

The two following cases represent the best and the worst results achieved in this series of patients. 

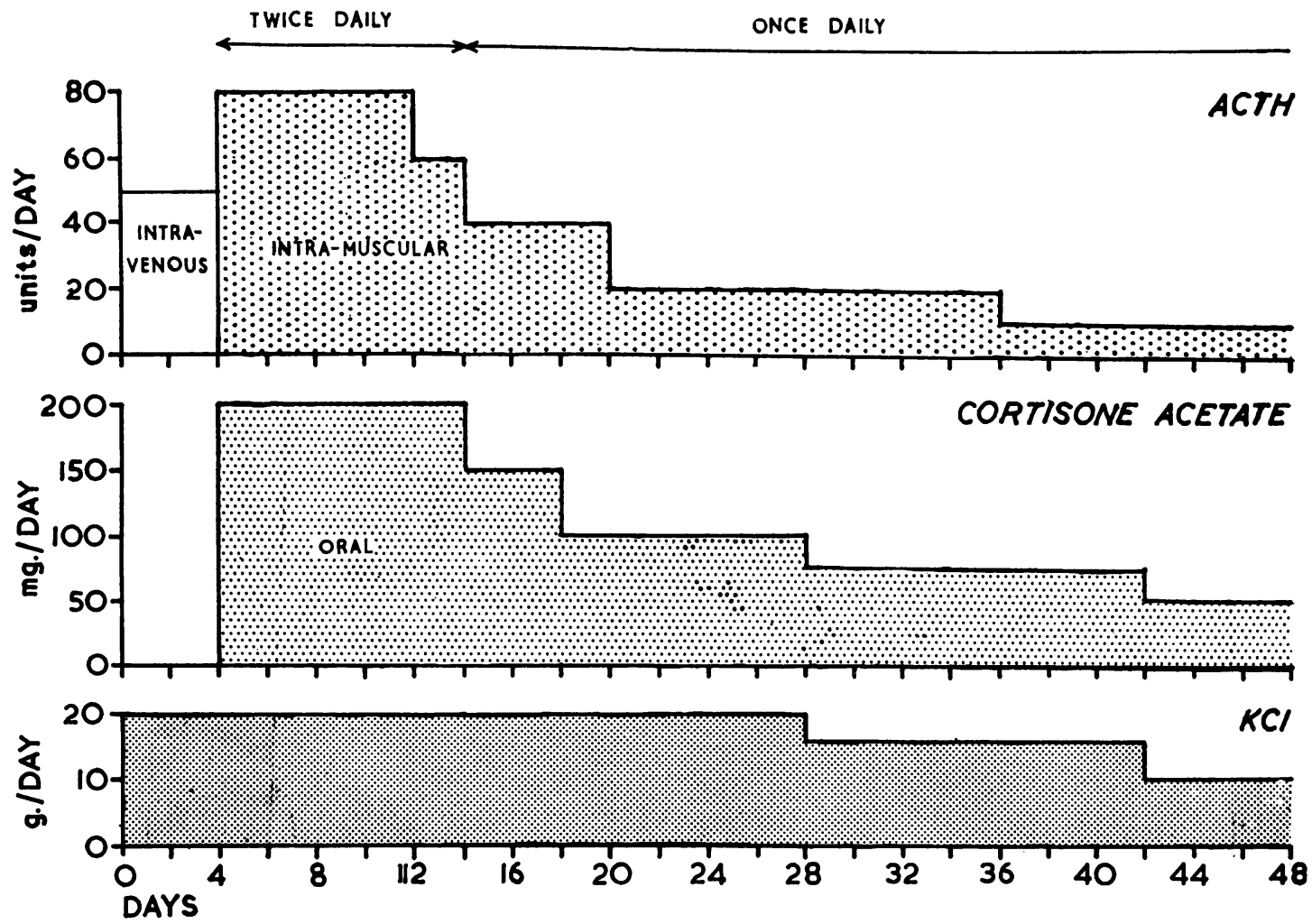

Figure.-Farly part of programme reasonably constant in most patients, but late portion varies greatly.

Case 1, a man aged 20, was one of the relatively early patients, having been admitted to the metabolic ward in August, 1950. He was the first individual in whom it was clearly obvious that changes in diet produced major modification of clinical and metabolic patterns during hormone administration (Kinsell and others, 1952). At the time of admission, he was so crippled as to be unable to continue with his classes at the university. During a prolonged period of intensive hormonal administration, on a diet containing large amounts of fat and inadequate amounts of protein, he developed a severe pneumonitis, from which he recovered slowly. He was discharged from the metabolic ward in October, 1951 , on a dosage of $37.5 \mathrm{mg}$. cortisone daily. After discharge he was able to take a part-time and eventually a full-time post as a draughtsman. At the present time, 4 years after the institution of therapy, his programme is college half-time, and work half-time, on a maintenance dosage of $25 \mathrm{mg}$. cortisone daily. Attempts to reduce the dosage below this level have been associated with the reappearance of joint symptoms.

Case 2, a woman aged 37, was first seen by us in May, 1952, at which time she had severe widespread arthritis, and severe unilateral iridocyclitis. Since then, she has been hospitalized five times. On two occasions, hun- dreds of units of intravenous ACTH and thousands of milligrams of cortisone or hydrocortisone have been required to bring her eye and joint manifestations under control. On several occasions this large dosage has been associated with significant disorientation, but fortunately this has been transient. If her problem had been one of joint involvement alone, we should probably have discontinued hormonal therapy, but to do so would almost certainly have resulted in the loss of one or both eyes.*

Fortunately, few individuals present as difficult a problem as the latter patient, but most require larger maintenance dosage than Case 1. The trend of dosage in the majority, however, is steadily downward. It is usually found that those whose dosage requirements continue high have failed to adhere to the prescribed programme of adequate rest and exercise, proper diet, and avoidance of emotional trauma.

* Since this was written, the patient has had a psychotic episode during very intensive hormonal therapy for an acute exacerbation, and hormonal therapy was stopped on June 8, 1954. There has since been no evidence of active arthritis or iridocyclitis up to the present time (September 19, 1954). 


\section{Experience with Other Forms of "Collagen Disease"}

It has also been attempted to attain complete suppression of disease in cases of lupus erythematosus, polyvasculitis, dermatomyositis, scleroderma, pemphigus, and rheumatic fever.

Pemphigus.-In the first patient so treated, a woman aged 46, who was in a near moribund condition after a year of steady progression of the disease, treatment was continued for more than a year in gradually decreasing amounts. She has been off all therapy for more than 2 years, and appears to be perfectly well.

Dermatomyositis.-The first patient, a woman aged 43, has been under continuous treatment since 1949; it has not been possible for her or any other patient in our small series to discontinue therapy, but the maintenance levels tend to be rather small.

Polyvasculitis.-Long-term complete suppression of the disease has not been achieved in any patient, but suppressive therapy of a magnitude compatible with full or nearly full activity has been possible in several.

Scleroderma.-The results were similar to the foregoing.

Lupus Erythematosus.-Almost without exception, a large dosage of the hormones has been necessary not only to produce but to maintain a reasonable degree of remission. Some patients have shown a remarkable tolerance for continued high dosages.

Rheumatic Fever.-All patients with an initial severe attack, having clinical or electrocardiographic evidence of carditis, are treated with sufficient amounts of ACTH and cortisone to bring down the sedimentation rate to normal levels, the objective being to protect the heart until the major force of the particular attack has spent itself. Treatment is decreased and discontinued as soon as feasible, usually in 3 to 4 weeks. The majority of patients who have had several attacks of the disease are treated only with aspirin and rest in bed. We are not at all certain that we have yet found the best approach to the problem.

\section{Discussion}

In a patient with rheumatoid arthritis, one may follow one of at least four courses insofar as hormonal therapy is concerned:

(1) No hormonal therapy whatever.

(2) A relaxed approach, with no attempt at regulating diet or other adjuvant measures, the patient being advised to "take one or several cortisone tablets when your joints hurt".

(3) A carefully regulated programme of diet and other measures, using minimal hormonal therapy in conjunc- tion with aspirin and other analgesics, designed to main- $\overparen{\Phi}$ tain a state of reasonable control.

(4) A programme of completely suppressive therapy, such as is outlined above.

All serious students of arthritis, and all who are interested in the use of the corticoids, will agree that $\frac{-}{-}$ the second procedure is to be avoided at all costs, $\frac{\overline{\bar{S}}}{\overline{\frac{5}{5}}}$ but at that point agreement stops.

It seems to us better to treat arthritics with $\varrho$ corticoids than to withhold such therapy, so long ${ }^{\infty}$ as both patient and physician are acutely aware of $\overrightarrow{0}$ two important facts:

(1) Hormonal therapy is in no sense the final answer to the disease;

(2) Such therapy carries with it the very real possibility? of certain untoward side-effects.

That we have chosen to use more intensive (suppressive) hormonal therapy than is advised by most workers, is probably attributable to the facto that we approached rheumatoid arthritis by way of a primary interest in the metabolic effects of hormones, instead of approaching the hormones by尺्ळ way of a primary interest in arthritis.

The objective of all those who are concerned in treating arthritic patients is to "hold the line" as best $\vec{c}$ we can until the final answers regarding cause amdon cure of the disease are found. Our definition of "holding the line" would be:

(a) Prevention of further joint damage;

(b) Restoration to a useful status;

(c) Avoidance of therapy which superimposes serious iatrogenic pathology upon the original arthritis.

Those who continue to rely entirely upon rest, physiotherapy, and aspirin, avoiding hormonal therapy, do so because of their serious concerno regarding the untoward effects of the latter.

Most of those who use the lowest hormonalo dosage compatible with a fair degree of comfort andं decrease in joint inflammation, do so because of their concern about the short-term and long-termo untoward side-effects of a larger dosage.

Those who use completely suppressive hormonal therapy, do so for the following reasons:

(1) With proper attention to diet and other adjuvan measures, the occurrence of untoward side-effects will probably be no greater than with the lower dosages required in analgesic hormonal therapy.

(2) The net amount of hormones administered over $\sigma$ a period of 2 or more years will probably be no greater than that used in the analgesic programme.

(3) The net salvage of patients is significantly greater? than can be achieved by the analgesic approach. 
More than 90 per cent. of the patients included in this report had "severe" arthritis, and there is not a "mild" case among them. Several of those who made a satisfactory response, had been considered as failures in terms of response to "analgesic" hormonal therapy. Several of our rheumatologist friends have been disturbed, because so far we have been unable to discontinue therapy in any patient, but the severity of the disease in this series of patients may be the explanation.

\section{Summary}

Suppressive hormonal therapy in 54 patients with severe rheumatoid arthritis was carried out for 4 years. On the basis of the experience gained it seems probable that:

(1) The "net salvage rate" of such patients is higher than could be achieved by the use of analgesic hormonal therapy.

(2) The total dosage of hormones over a period of 2 or more years, and the incidence of complications, is probably no greater than that observed with the analgesic approach, assuming that meticulous attention is paid to diet and other adjuvant measures.

\section{REFERENCES}

Hench, P. S., Kendall, E. C., Slocumb, C. H., and Polley, H. F. (1949). Proc. Mayo Clin., 24, 181.

Kinsell, L. W., Partridge, J., Boling, L., Margen, S., and Michaels, G. (1952). J. clin. Endocrinol., 12, 909.
Thérapie hormonale répressive comparée a l'analgésique des rhumatisants arthritiques

\section{RÉSUMÉ}

La thérapie hormonale répressive fut appliquée pendant 4 ans à 54 malades atteints d'arthrite rhumatismale grave. Selon l'expérience gagnée, il semble probable que:

(1) Le "pourcentage net de sauvetage" de tels malades est supérieur à celui qu'on pourrait obtenir par le traitement hormonal analgésique.

(2) La quantité totale d'hormones administrée pendant deux ans ou plus, ainsi que la fréquence des réactions secondaires ne sont probablement pas plus grandes qu'avec la méthode analgésique, pourvu que le régime alimentaire et les mesures adjuvantes soient l'objet des soins méticuleux.

Terapia hormonal supresora comparada con la analgésica en enfermos con artritis reumatoide

\section{SUMARIO}

Cincuenta y cuatro enfermos con artritis reumatoide fueron sometidos durante 4 años a la terapia hormonal supresora. A base de la experiencia ganada parece probable que:

(1) La "proporción neta de salvamento" de tales enfermos es superior a la que se pudiera alcanzar por la terapia hormonal analgésica.

(2) $\mathrm{La}$ cantidad total de hormonas administrada durante dos años o más, así como la frecuencia de fenómenos secundarios no exceden probablementes las observadas con el empleo del sistema analgésico, provisto que se ponga atención meticulosa en el régimen alimenticio y las medidas coadyuvantes. 